\title{
Article \\ Exacerbations and Changes in Physical Activity and Sedentary Behaviour in Patients with Bronchiectasis after 1 Year
}

\author{
Victoria Alcaraz-Serrano ${ }^{1}$ (D) Ane Arbillaga-Etxarri ${ }^{2}$, Patricia Oscanoa ${ }^{3}$, Laia Fernández-Barat ${ }^{1}$ (D), \\ Leticia Bueno $^{1}\left(\mathbb{D}\right.$, Rosanel Amaro ${ }^{3}$, Elena Gimeno-Santos $4,5, *,+\mathbb{D}$ and Antoni Torres $1,3,+(\mathbb{D}$
}

1 Fundació Clínic per la Recerca Biomèdica (FCRB), CIBERES, Hospital Clínic de Barcelona, Villarroel Street 170, 08036 Barcelona, Spain; victoriaalcarazserrano@gmail.com (V.A.-S.); lfernan1@clinic.cat (L.F.-B.); bueno@clinic.cat (L.B.); atorres@clinic.cat (A.T.)

2 Physiotherapy Department, University of Deusto, Mundaiz Street 50, 20012 Donostia San Sebastián, Gipuzkoa, Spain; ane.arbillaga@deusto.es

3 Institut Clínic Respiratori, Hospital Clínic de Barcelona, Villarroel Street 170, 08036 Barcelona, Spain; oscanoa@clinic.cat (P.O.); ramaro@clinic.cat (R.A.)

4 Institut d'Investigacions Biomèdiques August Pi i Sunyer (IDIBAPS), Hospital Clinic de Barcelona, Villarroel Street 170, 08036 Barcelona, Spain

5 Non-Communicable Diseases and Environment Department, Barcelona Institute for Global Health (ISGlobal). Dr. Aiguader Street 88, 08003 Barcelona, Spain

* Correspondence: elenagimeno@gmail.com

+ Both authors contributed equally to the manuscript.

Citation: Alcaraz-Serrano, V.; Arbillaga-Etxarri, A.; Oscanoa, P.; Fernández-Barat, L.; Bueno, L.; Amaro, R.; Gimeno-Santos, E.; Torres,

A. Exacerbations and Changes in Physical Activity and Sedentary Behaviour in Patients with Bronchiectasis after 1 Year. J. Clin. Med. 2021, 10, 1190. https://doi.org/ $10.3390 / \mathrm{jcm} 10061190$

Academic Editors: Pierachille Santus and Raquel Sebio García

Received: 9 February 2021

Accepted: 10 March 2021

Published: 12 March 2021

Publisher's Note: MDPI stays neutral with regard to jurisdictional claims in published maps and institutional affiliations.

Copyright: (c) 2021 by the authors. Licensee MDPI, Basel, Switzerland. This article is an open access article distributed under the terms and conditions of the Creative Commons Attribution (CC BY) license (https:// creativecommons.org/licenses/by/ $4.0 /)$

\begin{abstract}
Background: Low physical activity and high sedentary behaviour in patients with bronchiectasis are associated with hospitalisation over one year. However, the factors associated with longitudinal changes in physical activity and sedentary behaviour have not been explored. We aimed to identify clinical and sociodemographic characteristics related to a change in physical activity and sedentary behaviour in patients with bronchiectasis after one year. Methods: This was a prospective observational study during which physical activity measurements were recorded using a SenseWear Armband for one week at baseline and at one year. At each assessment point, patients were classified as active or inactive (measured as steps per day) and as sedentary or not sedentary (measured as sedentary time). Results: 53 patients with bronchiectasis were analysed, and after one year, 18 (34\%) had worse activity and sedentary levels. Specifically, 10 patients became inactive and sedentary. Multivariable analysis showed that the number of exacerbations during the follow-up period was the only outcome independently associated with change to higher inactivity and sedentary behaviour (odds ratio (OR), 2.19; 95\% CI, 1.12 to 4.28). Conclusions: The number of exacerbations in patients with bronchiectasis was associated with changes in physical activity and sedentary behaviour. Exacerbation prevention may appear as a key factor in relation to physical activity and sedentary behaviour in patients with bronchiectasis.
\end{abstract}

Keywords: bronchiectasis; physical activity; sedentary behaviour; exacerbation

\section{Introduction}

Bronchiectasis is a chronic respiratory disease characterised by chronic productive cough, dyspnoea, and frequent exacerbations [1]. An exacerbation is defined as a person with bronchiectasis with a deterioration in three or more of the following key symptoms for at least $48 \mathrm{~h}$ : cough, sputum volume and/or consistency, sputum purulence, breathlessness and/or exercise tolerance, fatigue and/or malaise, haemoptysis; and a clinician determines that a change in treatment is required [2]. Exacerbations increase the severity of microbiological, radiological, and functional outcomes [3], being differentiated into mild, when patients are treated with oral antibiotics as outpatients, and moderate to severe, when they require hospitalisation and intravenous therapy [4]. Furthermore, a higher frequency of exacerbations is associated with an increased risk of mortality [5]. 
It is known that in patients with chronic obstructive pulmonary disease (COPD), high levels of physical activity and low time in sedentary behaviour are at a reduced risk of exacerbations and reduced health care utilisation, which leads to various cost savings [6,7]. By contrast, there is limited knowledge of the relation between physical activity, sedentary behaviour, and exacerbations in patients with bronchiectasis. It was recently described that patients with bronchiectasis who spent $\geq 7.8 \mathrm{~h} /$ day in sedentary behaviour were at a 5.9 times greater risk of future severe exacerbations [8]. Physical activity is a complex behaviour structured in variables according to different intensities and outcomes [9]. Although steps per day and time spent in sedentary behaviour are strongly correlated, they should be considered independently because they each have their own peculiarities and associated factors [10]. To date, the factors associated with the modification in physical activity and sedentary behaviour after one year have not been explored for either measure in patients with bronchiectasis.

Therefore, the aim of this study was to analyse the clinical and sociodemographic characteristics associated with a change in physical activity and sedentary behaviour after one year in patients with bronchiectasis.

\section{Materials and Methods}

\subsection{Study Design}

This was a prospective observational study conducted at the pulmonology service of a tertiary care hospital in Barcelona, Spain. Physical activity and sedentary behaviour measurements were performed at baseline and at one year follow-up to study the distribution of groups (active/inactive and sedentary/not sedentary) and their longitudinal modification. We also investigated the clinical and sociodemographic factors potentially related to a shift between physical activity and sedentary behaviour levels. The inclusion criteria were as follows: (1) adults ( $\geq 18$ years of age) diagnosed with bronchiectasis, as confirmed by computed tomography and with symptoms of the disease; (2) clinical stability (no exacerbations and no significant change in symptoms and/or medication in the last four weeks); (3) the ability to perform all the clinical tests and understand the process and the purposes of the study; (4) willing to give informed consent. Exclusion criteria were: (1) any physical or psychological disorder that might interfere with protocol compliance; (2) diagnosis of cystic fibrosis, sarcoidosis, pulmonary fibrosis, active tuberculosis (TB), or non-TB mycobacterial infection in treatment; (3) participation in a pulmonary rehabilitation (PR) programme in the last year; 4) respiratory insufficiency and/or oxygen therapy; (5) missing data after 12 months of follow-up.

The study was approved by the Clinical Research Ethics Committee of the Hospital Clinic (Ethics Approval Reference: HCB/2016/0012). Informed consent was obtained from all subjects involved in the study.

\subsection{Measurements}

Patients were assessed at baseline and after one year, with no intervention provided during this year. Dyspnoea was measured using the modified Medical Research Council (mMRC) scale [11]. Lung function was assessed with an EasyOne ${ }^{\mathrm{TM}}$ World Spirometer (NDD Medical Technologies, Zurich, Switzerland) and classified according to the American Thoracic Society/European Respiratory Society Guidelines [12]. Exercise capacity was measured using the 6-min walking test (6MWT) [13]. Quality of life was assessed using the Quality-of-Life Bronchiectasis questionnaire (QoL-B) [14], while the impact of coughing on the quality of life was assessed with the Leicester Cough Questionnaire (LCQ) [15]. Bronchiectasis severity was assessed using the Bronchiectasis Severity Index (BSI) Score [16]. We recorded the number of exacerbations and hospitalisations in the medical dataset during the follow-up based on a consensus definition [2]. Frequency of exacerbations for subanalysis was divided into $0,1-2$, and $\geq 3$ exacerbations during the follow-up [17].

Physical activity and sedentary behaviour were measured using a tri-axial accelerometer, the SenseWear Armband (SWA) (BodyMedia Inc., Pittsburgh, PA, USA). Participants 
were asked to wear the SWA for the maximum time possible over seven days, except during water-based activities. It was worn in the triceps area, on the rear of the dominant arm [18] Intensity of physical activity was reported as metabolic equivalents (METs) and classified into sedentary ( $\leq 1.5 \mathrm{MET})$, light $(1.6$ to $<3.0 \mathrm{MET})$, moderate ( 3.0 to $<6.0 \mathrm{MET})$, and vigorous ( $\geq 6.0$ MET) [19]. The mean time (in minutes) spent at each intensity level was recorded. Moderate-to-vigorous physical activity (MVPA) was calculated as the mean number of minutes spent in moderate and vigorous physical activity on the valid days. Sedentary time was analysed as the number of minutes the patient spent at $\leq 1.5$ MET intensity.

Patients were classified into four groups according to their physical activity and sedentary behaviour levels at baseline and at one year. The cut-off for being active was $\geq 6290$ steps per day and for being sedentary $\geq 7.8 \mathrm{~h}$ per day spent in sedentary behaviour [8]. The groups were labelled from the best to worst, as follows: 'active + not sedentary', 'active + sedentary', 'inactive + not sedentary', 'inactive + sedentary'. The dependent variable was the change, after one year follow-up, to the worst group 'inactive + sedentary'.

\subsection{Statistical Analysis}

Data are presented as numbers (\%) for categorical variables, as means \pm standard deviations (SD) for normally distributed data and as medians $\left(\mathrm{P}_{25}-\mathrm{P}_{75}\right)$ (1st and 3rd quartiles) for non-normally distributed data. The assumption of normality was checked by means of Shapiro-Wilk tests. Comparisons of categorical variables were performed using the chi-square test. Comparisons between continuous variables were performed by analysis of variance (ANOVA) or the Kruskal-Wallis test. If the overall ANOVA (or Kruskal-Wallis) result was significant, we conducted post-hoc pairwise comparisons with Bonferroni correction to control for the experiment-wise error rate.

Logistic regression analyses [20] were used to examine the associations between the change to 'inactive + sedentary' and the various risk factors. In the first step, each risk factor, together with the numbers of hospitalisations and exacerbations during the follow-up, were tested individually. We included age, 6-min walking distance, and forced expiratory volume in the first second predicted $\left(\mathrm{FEV}_{1} \%\right)$ as risk factors. In the second step, all risk factors that showed an association in the univariate model $(p<0.10)$ were added to the multivariable model. Finally, a backward stepwise selection (likelihood ratio) (pin $<0.05$, pout $>0.10$ ) was used to determine factors associated with change to the 'inactive + sedentary' group after one year [21]. Multicollinearity was assessed by calculating the variance inflation factor, and we calculated the odds ratios (ORs) and their 95\% confidence intervals (CIs). The Hosmer-Lemeshow goodness-of-fit test was performed to assess the overall fit of the final model. The internal validity of the final model was assessed using ordinary non-parametric bootstrapping with 1000 bootstrap samples and bias-corrected, accelerated 95\% CIs.

The level of significance was set at 0.05 (two-tailed) for all analyses, which were performed using IBM SPSS Statistics 26.0 (IBM Corp., Armonk, NY, USA).

\section{Results}

\subsection{Baseline Data}

Of the 72 patients with bronchiectasis who we recruited, 53 (37 females, mean age $62 \pm 16$ years) were included in the analysis (Figure 1 ).

Their baseline sociodemographic and clinical characteristics are shown in Table 1, with 24 in the 'active + not sedentary' group, 3 in the 'active + sedentary' group, 11 in the 'inactive + not sedentary' group, and 15 in the 'inactive + sedentary' group. There were only differences in physical activity outcomes where the group 'inactive + sedentary' had the lowest values of light and moderate physical activity, MVPA and steps per day, as well as the highest value for sedentary time. 
Table 1. Baseline characteristics by physical activity and sedentary behaviour classification.

\begin{tabular}{|c|c|c|c|c|c|c|}
\hline & All Patients & $\begin{array}{c}\text { 'Active + } \\
\text { Not } \\
\text { Sedentary' }\end{array}$ & $\begin{array}{c}\text { 'Active + } \\
\text { Sedentary' }\end{array}$ & $\begin{array}{c}\text { 'Inactive + } \\
\text { Not } \\
\text { Sedentary' }\end{array}$ & $\begin{array}{l}\text { 'Inactive + } \\
\text { Sedentary' }\end{array}$ & $p$ Value \\
\hline & $\mathrm{N}=53$ & $24(45)$ & $3(6)$ & $11(21)$ & $15(28)$ & \\
\hline \multicolumn{7}{|l|}{ Demographics } \\
\hline Female & $37(70)$ & $19(79)$ & $1(33.3)$ & 7 (63.6) & $10(66.6)$ & 0.368 \\
\hline Age, years & $62.3(15.9)$ & $58.7(14.9)$ & $62.7(6.4)$ & $64.6(21.9)$ & $66.1(13.9)$ & 0.523 \\
\hline $\mathrm{BMI}, \mathrm{Kg} / \mathrm{m}^{2}$ & $24.3(4.1)$ & $23.8(3.9)$ & $29.4(5.1)$ & $23.9(2.9)$ & $24.1(4.6)$ & 0.174 \\
\hline Work activity & & & & & & 0.263 \\
\hline Active & $19(36)$ & $12(50)$ & $1(33.3)$ & $2(18.2)$ & $4(26.7)$ & \\
\hline Retired & $34(64)$ & $12(50)$ & $2(66.6)$ & $9(81.8)$ & $11(73.3)$ & \\
\hline Smoking habit & & & & & & 0.538 \\
\hline Active smoker & $1(2)$ & $1(4.2)$ & $0(0)$ & $0(0)$ & $0(0)$ & \\
\hline Former smokers & $14(26)$ & $4(16.6)$ & $2(66.6)$ & $3(27.2)$ & $5(33.3)$ & \\
\hline Non-smoker & $38(71.7)$ & $19(79.2)$ & $1(33.3)$ & $8(72.7)$ & $10(66.6)$ & \\
\hline Chronic colonisation & $20(37)$ & $5(20.8)$ & $1(33.3)$ & $6(51.5)$ & $8(53.3)$ & 0.121 \\
\hline Pseudomonas aeruginosa & $16(30)$ & $3(60)$ & $1(100)$ & $5(83.3)$ & $7(87.5)$ & 0.081 \\
\hline Dyspnoea (mMRC Scale, 0-4) & $1[1,1]$ & $1[0,1]$ & $1[1,1]$ & $1[1,2]$ & $1[1,2]$ & 0.263 \\
\hline No. exacerbations previous year & $1[0,1,2]$ & $1[0,1,2]$ & $1[0,1]$ & $2[0,1,2]$ & $1[0,1,2,3,4]$ & 0.283 \\
\hline No. hospitalizations previous year & $0[0,0]$ & $0[0,0]$ & $0[0,0]$ & $0[0,0]$ & $0[0,1]$ & 0.653 \\
\hline $\begin{array}{c}\text { Number of lobes affected in CT } \\
\text { scan }\end{array}$ & $3.62(1.6)$ & $3.50(1.7)$ & $2.33(0.6)$ & $3.91(1.3)$ & $3.86(1.7)$ & 0.350 \\
\hline \multicolumn{7}{|l|}{ Aetiology } \\
\hline Post-infectious & $24(45)$ & $15(62.5)$ & $0(0)$ & $6(54.5)$ & $3(20)$ & 0.022 \\
\hline Idiopathic & $13(24)$ & $3(12.5)$ & $2(66.6)$ & $2(18)$ & $6(40)$ & 0.074 \\
\hline Others & $16(30.2)$ & $6(25)$ & $1(33.3)$ & $3(27.3)$ & $6(40)$ & 0.789 \\
\hline \multicolumn{7}{|l|}{ Severity } \\
\hline BSI stages & $2[1,2,3]$ & $2[1,2]$ & $2[1,2]$ & $2[2,3]$ & $3[1,2,3]$ & 0.086 \\
\hline \multicolumn{7}{|l|}{ Pulmonary function } \\
\hline FEV1, \% predicted & $73.2(20)$ & $80.9(18.2)$ & $67(5.56)$ & $68.9(23.1)$ & $65.4(19.9)$ & 0.086 \\
\hline FVC, $\%$ predicted & $81(18.3)$ & $87.2(16.4)$ & $90.3(38.6)$ & $72.36(14.3)$ & $75.6(16.5)$ & 0.059 \\
\hline FEV1/FVC, \% & $85.9(18)$ & $89.1(17.2)$ & $73(17.7)$ & $84.9(19.4)$ & $84.2(18.6)$ & 0.490 \\
\hline 6MWT, metres & $516.8(97.8)$ & $534.3(80.03)$ & $564.8(40.5)$ & $512.8(103.4)$ & $482.3(122.01)$ & 0.345 \\
\hline \multicolumn{7}{|l|}{ Physical activity } \\
\hline Light (min per day) & $216.7(77)$ & $237.2(71.6)$ & $138.8(64.4)$ & $256.6(91.9)$ & $170.2(37.6)$ & $0.002^{a, b}$ \\
\hline Moderate (min per day) & $112(76)$ & $143.3(91.1)$ & $97.2(24.5)$ & $117.5(57.4)$ & $60.8(30.1)$ & $0.008^{a}$ \\
\hline Vigorous (min per day) & $0.66(1.7)$ & $1.1(2.3)$ & $0(0)$ & $0.26(0.31)$ & $0.44(1.0)$ & 0.445 \\
\hline MVPA (min per day) & $112.5(77)$ & $144(92.1)$ & $97.2(24.5)$ & $117.7(57.5)$ & $61.2(30.5)$ & $0.009^{\mathrm{a}}$ \\
\hline Steps per day & $6759(3530)$ & $9441(3014)$ & $8912(549)$ & $4840(1120)$ & 3444 (1563) & $<0.001$ \\
\hline Sedentary time $(\mathrm{min})$ & $430(99.8)$ & $374.4(75.7)$ & $487.5(18.4)$ & $384.9(79.8)$ & $541(46.6)$ & $<0.001^{\mathrm{a}, \mathrm{b}}$ \\
\hline \multicolumn{7}{|c|}{ Quality of Life Bronchiectasis Questionnaire } \\
\hline Physical Function & $60.4(32.7)$ & $62.3(33.3)$ & $55.5(19.2)$ & $45.5(34.2)$ & $64.4(32)$ & 0.382 \\
\hline Role Function & $76.7(26.6)$ & $83.3(26)$ & $66.6(0)$ & $75.7(26.2)$ & $68.9(29.5)$ & 0.367 \\
\hline Vitality & $59.4(26.8)$ & $62.5(24.7)$ & $55.6(19.2)$ & $65.2(24)$ & $51.1(33)$ & 0.521 \\
\hline Emotional Function & $74.2(28.9)$ & $75.7(27.4)$ & $61.1(25.4)$ & $69.7(34)$ & $77.8(30)$ & 0.771 \\
\hline Social Function & $69.8(30.8)$ & $76.4(24.5)$ & $55.6(38.5)$ & $65.2(36.9)$ & $65.6(34.7)$ & 0.530 \\
\hline Treatment Burden & $72.9(39.8)$ & $72.2(42.5)$ & $66.7(57.7)$ & $69.7(37.8)$ & $77.7(37)$ & 0.948 \\
\hline Health Perceptions & $53.1(26.7)$ & $61.8(28.4)$ & $50(16.7)$ & $51.5(24.1)$ & $41.4(24.3)$ & 0.129 \\
\hline Respiratory Symptoms & $76.7(23.2)$ & $77.7(23.4)$ & $66.7(33.3)$ & $78.8(22.5)$ & $75.6(23.5)$ & 0.981 \\
\hline \multicolumn{7}{|c|}{ Leicester Cough Questionnaire } \\
\hline Total & $15.3(4.64)$ & $16.04(4.2)$ & $12.9(7.2)$ & $15.1(5.5)$ & $14.8(4.5)$ & 0.678 \\
\hline Physical & $4.9(1.34)$ & $5.2(1.2)$ & $4.37(2.3)$ & $5.03(1.3)$ & $4.74(1.5)$ & 0.616 \\
\hline Psychological & $5.01(1.74)$ & $5.2(1.6)$ & $4.19(2.4)$ & $4.78(2.2)$ & $5.04(1.6)$ & 0.773 \\
\hline Social & $5.44(1.8)$ & $5.67(1.6)$ & $4.41(2.7)$ & $5.3(2.2)$ & $5.4(1.6)$ & 0.710 \\
\hline
\end{tabular}

Abbreviations: 6MWT, 6-min walking test; BMI, body mass index; BSI, bronchiectasis severity index; CT: computed tomography; FEV $_{1}$, forced expiratory volume in $1 \mathrm{~s} ; \mathrm{FVC}$, forced vital capacity; Kg, kilogram; m, metre; min: minutes; mMRC, modified Medical Research Council scale; MVPA, moderate-to-vigorous physical activity. Data are presented as n (\%), mean $\pm \mathrm{SD}$ or median $\left(\mathrm{P}_{25}-\mathrm{P}_{75}\right) .{ }^{\mathrm{a}} p<0.05$ for comparison between 'active + not sedentary' vs. 'inactive + sedentary'. ${ }^{b} p<0.05$ for comparison between 'inactive + sedentary' vs. 'inactive + not sedentary'. 


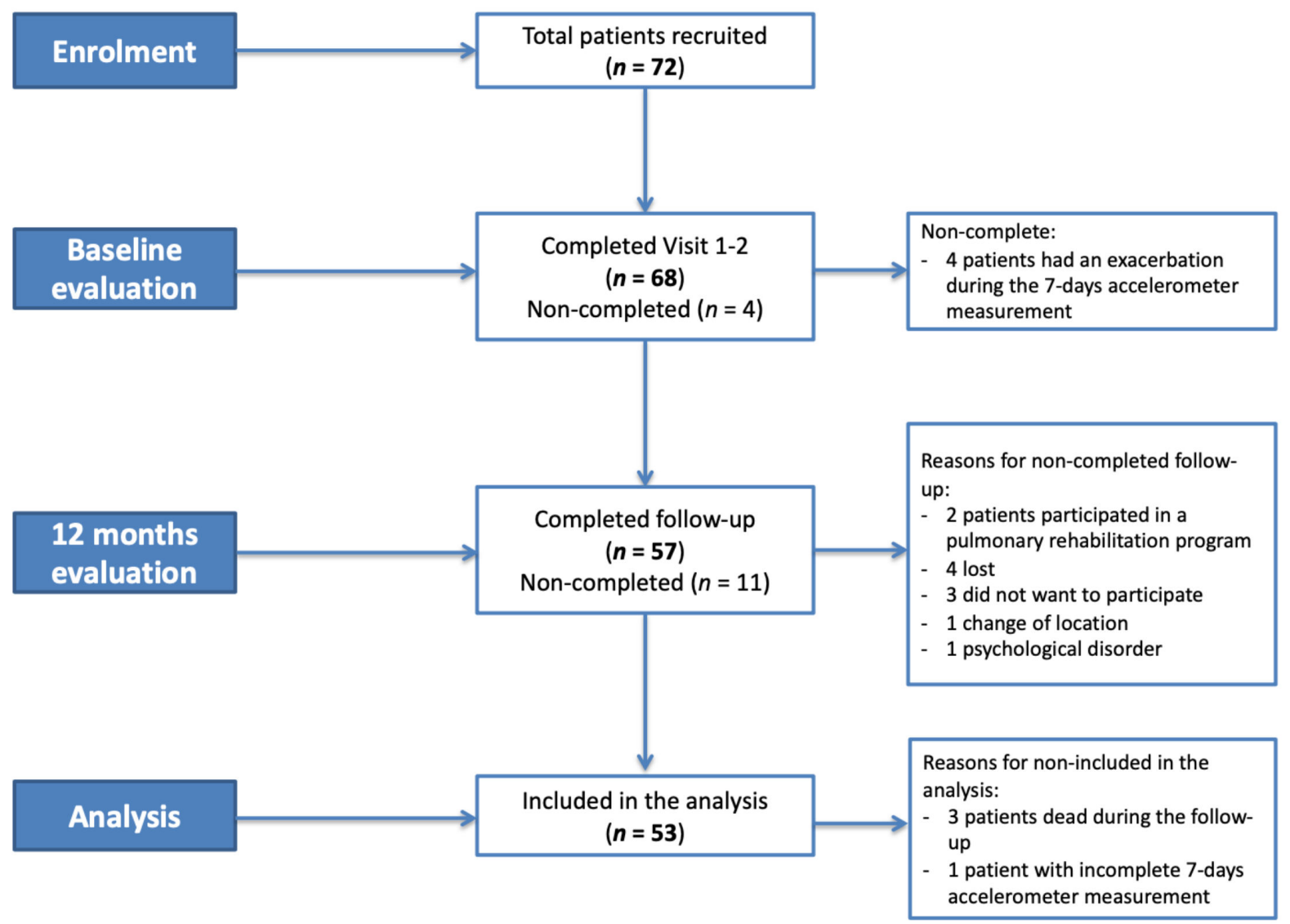

Figure 1. Enrolment flow-chart.

\subsection{Follow-Up Assessment at 1 Year}

After one year follow-up, the number of patients in each group changed to 18 in the 'active + not sedentary' group, 7 in the 'active + sedentary' group, 8 in the 'inactive + not sedentary' group, and 20 in the 'inactive + sedentary' group. In total, 27 (51\%) patients changed to a different group, of whom only $9(17 \%)$ improved from a sedentary and/or inactive group to a not sedentary and/or active group. The other $18(34 \%)$ patients deteriorated, and 10 of these shifted to the worst group ('inactive + sedentary'). At this time, the 'inactive + sedentary' group had more exacerbations, lower physical activity levels, and worse quality of life (Table 2).

Table 2. Follow-up characteristics by physical activity and sedentary behaviour classification.

\begin{tabular}{|c|c|c|c|c|c|c|}
\hline & All Patients & $\begin{array}{c}\text { 'Active + } \\
\text { Not } \\
\text { Sedentary' }\end{array}$ & $\begin{array}{l}\text { 'Active + } \\
\text { Sedentary' }\end{array}$ & $\begin{array}{c}\text { 'Inactive + } \\
\text { Not } \\
\text { Sedentary' }\end{array}$ & $\begin{array}{l}\text { 'Inactive + } \\
\text { Sedentary' }\end{array}$ & $p$ Value \\
\hline & $\mathrm{N}=53$ & $18(34)$ & $7(13)$ & $8(15)$ & $20(38)$ & \\
\hline \multicolumn{7}{|l|}{ Demographics } \\
\hline BMI, $\mathrm{Kg} / \mathrm{m}^{2}$ & $24.2(4.3)$ & $25.1(4.2)$ & $24.2(4.6)$ & $21.6(4.1)$ & $24.7(4.4)$ & 0.287 \\
\hline Dyspnoea (mMRC Scale, 0-4) & $1[0,1]$ & $1[0,1,2]$ & 1 [0.75-2.25] & $2[0,1,2,3]$ & $3[2,3,4]$ & 0.075 \\
\hline No. exacerbations during FUP & $2[1,2,3]$ & $1[0,1,2]$ & $1[0.75-2.25]$ & $2[0,1,2,3]$ & $3[2,3,4]$ & $<0.001$ \\
\hline No. hospitalisations during FUP & $0[0-0.5]$ & $0[0,0]$ & $0[0,0]$ & $0[0-0.75]$ & $0[0,1]$ & 0.125 \\
\hline \multicolumn{7}{|l|}{ Pulmonary function } \\
\hline $\mathrm{FEV}_{1}, \%$ predicted & $69.5(20.4)$ & $75.5(19.4)$ & $73.8(22.4)$ & $64.1(23.2)$ & $66.7(19.1)$ & 0.363 \\
\hline FVC, $\%$ predicted & $77.7(17.8)$ & $82.4(16.6)$ & $77.4(13.5)$ & $72.7(23.1)$ & $76.5(18.2)$ & 0.256 \\
\hline $\mathrm{FEV}_{1} / \mathrm{FVC}, \%$ & $83.7(18.3)$ & $83.9(14.8)$ & $93(20.5)$ & $87.4(30.7)$ & $81.9(13.3)$ & 0.532 \\
\hline
\end{tabular}


Table 2. Cont.

\begin{tabular}{|c|c|c|c|c|c|c|}
\hline & All Patients & $\begin{array}{c}\text { 'Active + } \\
\text { Not } \\
\text { Sedentary' }\end{array}$ & $\begin{array}{c}\text { 'Active + } \\
\text { Sedentary' }\end{array}$ & $\begin{array}{c}\text { 'Inactive + } \\
\text { Not } \\
\text { Sedentary' }\end{array}$ & $\begin{array}{l}\text { 'Inactive + } \\
\text { Sedentary' }\end{array}$ & $p$ Value \\
\hline 6MWT, metres & $520.4(98.5)$ & $540.3(77.2)$ & $582.9(81.2)$ & $505.4(73.9)$ & $470.8(111.8)$ & 0.068 \\
\hline \multicolumn{7}{|l|}{ Physical activity } \\
\hline Light (min per day) & $205.4(75.5)$ & $248.2(86.1)$ & $164.8(37.1)$ & $206.1(86.4)$ & $179.2(53.7)$ & $0.016^{\mathrm{a}}$ \\
\hline Moderate (min per day) & $107.6(84.2)$ & $160.2(95.7)$ & $86.2(36.3)$ & $155.7(88.8)$ & $49.8(24.6)$ & $<0.001^{a, c}$ \\
\hline Vigorous (min per day) & $0.89(2.51)$ & $1.9(3.9)$ & $1.14(2.3)$ & $0.5(0.67)$ & $0.04(0.14)$ & 0.123 \\
\hline MVPA (min per day) & $108.5(85.1)$ & $162.2(96.6)$ & $87.3(37.4)$ & $156.2(89.4)$ & $49.9(24.6)$ & $<0.001$ \\
\hline Steps per day & 6781 (5799) & $10443(2681)$ & $8073(1624)$ & 4383 (1764) & $3983(1484)$ & $<0.001^{\mathrm{a}, \mathrm{c}}$ \\
\hline Sedentary time (min) & $441.2(115.6)$ & $337.9(72.1)$ & $501.3(30.3)$ & $372.6(117.1)$ & $540.2(53.3)$ & $<0.001$ \\
\hline \multicolumn{7}{|c|}{ Quality of Life Bronchiectasis Questionnaire } \\
\hline Physical Function & $53.14(31.8)$ & $61.1(23.6)$ & $72.2(25.1)$ & $50(34.7)$ & $35.1(32.3)$ & 0.026 \\
\hline Role Function & $72.01(29.56)$ & $81.5(23.5)$ & $94.4(13.6)$ & $61.9(12.6)$ & $57(35.7)$ & $0.012^{\mathrm{a}, \mathrm{b}}$ \\
\hline Vitality & $59.4(22.98)$ & $61.1(21.4)$ & $63.8(16.4)$ & $66.7(21.5)$ & $50.8(25.7)$ & 0.215 \\
\hline Emotional Function & $74.5(27.5)$ & $73.1(24.3)$ & $88.9(17.2)$ & $80.9(26.2)$ & $66.7(33.3)$ & 0.295 \\
\hline Social Function & $64.5(31.4)$ & $78.7(23.4)$ & $75(20.4)$ & $54.7(20.9)$ & $48.2(37.6)$ & $0.030^{\mathrm{a}}$ \\
\hline Treatment Burden & $69.9(37.8)$ & $75.9(35.8)$ & $72.2(44.3)$ & $52.4(42.4)$ & $68.4(37.6)$ & 0.590 \\
\hline Health Perceptions & $55.3(28.8)$ & $62.9(27.1)$ & $63.9(6.8)$ & $57.1(26.9)$ & $42.1(32.6)$ & 0.101 \\
\hline Respiratory Symptoms & $74.8(23.5)$ & $77.8(19.8)$ & $72.2(13.6)$ & $85.7(17.8)$ & $66.7(29.4)$ & 0.164 \\
\hline \multicolumn{7}{|c|}{ Leicester Cough Questionnaire } \\
\hline Total & $15.5(4.4)$ & $15.9(4.4)$ & $17.3(2.2)$ & $16.1(3.8)$ & $14.2(5.1)$ & 0.348 \\
\hline Physical & $4.98(1.4)$ & $5.24(1.2)$ & $5.6(0.8)$ & $5.1(1.3)$ & $4.5(1.6)$ & 0.238 \\
\hline Psychological & $5.23(1.7)$ & $5.4(1.7)$ & $5.8(0.8)$ & $5.4(1.5)$ & $4.7(1.9)$ & 0.426 \\
\hline Social & $5.36(1.6)$ & $5.5(1.5)$ & $5.9(0.9)$ & $5.6(1.3)$ & $4.9(1.8)$ & 0.348 \\
\hline
\end{tabular}

Abbreviations: 6MWT, 6-min walking test; BMI, body mass index; $\mathrm{FEV}_{1}$, forced expiratory volume in $1 \mathrm{~s}$; FVC, forced vital capacity; FUP, follow-up; Kg, kilogram; m, metre; min: minutes; mMRC, modified Medical Research Council scale; MVPA, moderate-to-vigorous physical activity. Data are presented as $\mathrm{n}(\%)$, mean $\pm \mathrm{SD}$ or median $\left(\mathrm{P}_{25}-\mathrm{P}_{75}\right)$. ${ }^{a} p<0.05$ for comparison between 'active + not sedentary' vs. 'inactive + sedentary'. ${ }^{\mathrm{b}} p<0.05$ for comparison between 'inactive + sedentary' vs. 'active + sedentary'. ${ }^{\mathrm{c}} p<0.05$ for comparison between 'inactive + not sedentary' vs. 'inactive + sedentary'.

\subsection{Factors Associated with the Shift to Reduced Activity Levels}

Results from the multivariable analysis showed that the number of exacerbations during the follow-up (OR, 2.19; 95\% CI, 1.12 to 4.28$)$ was independently associated with change to the 'inactive + sedentary' group (Table 3). Internal validation of the logistic regression model using bootstrapping with 1000 samples demonstrated robust results for the variable included in the model, with small $95 \%$ CIs around the original coefficients.

Table 3. Significant risk factors for inactivity and sedentary behaviour in the logistic regression analyses.

\begin{tabular}{|c|c|c|c|c|c|c|}
\hline \multirow{2}{*}{ Variable } & \multicolumn{3}{|c|}{ Univariate $^{a}$} & \multicolumn{3}{|c|}{ Multivariable $^{b}$} \\
\hline & OR & $95 \%$ CI & $p$ Value & OR & $95 \%$ CI & $p$ Value \\
\hline Age $(+1$ year $)$ & 1.003 & 0.96 to 1.05 & 0.906 & - & - & - \\
\hline 6-min walking distance $(+1 \mathrm{~m})$ & 0.998 & 0.99 to 1.00 & 0.518 & - & - & - \\
\hline $\mathrm{FEV}_{1}(+1 \%$ predicted $)$ & 1.005 & 0.97 to 1.04 & 0.796 & - & - & - \\
\hline Number of hospitalisations during FUP (+1 unit) & 1.200 & 0.80 to 1.793 & 0.089 & - & - & - \\
\hline Number of exacerbations during FUP (+1 unit) & 1.540 & 1.23 to 2.65 & 0.045 & 2.192 & 1.12 to 4.28 & 0.021 \\
\hline
\end{tabular}

Abbreviations: $\mathrm{CI}$, confidence interval; $\mathrm{FEV}_{1}$, forced expiratory volume in $1 \mathrm{~s}$; FUP, follow-up; OR, odds ratio. The OR represents the odds that the change of group to 'inactive + sedentary' will occur with exposure to the explanatory variable, against the odds of the outcome occurring in the absence of that exposure. The $p$-value is based on the null hypothesis that all ORs relating to an explanatory variable equal unity (i.e., no effect). ${ }^{\text {a }}$ The variables analysed in the univariate analysis were age, 6-min walking distance, $\mathrm{FEV}_{1} \%$ predicted, number of hospitalisations during the follow-up and number of exacerbations during the follow-up. ${ }^{\mathrm{b}}$ Hosmer-Lemeshow goodness-of-fit test, $p=0.76$.

\subsection{Relationship between Baseline and Follow-Up Activity Levels by Number of Exacerbations}

In the final cohort, $11(21 \%)$ patients had 0 exacerbations, 25 (47\%) had 1-2 exacerbations, and $17(32 \%)$ had $\geq 3$ exacerbations. The physical activity and sedentary behaviour variables at baseline and at one year, together with the $p$-trend for each parameter, are 
shown in Figure 2. At both evaluations, the group with $\geq 3$ exacerbations had the lowest MVPA, lowest number of steps per day and the highest sedentary time compared with the other two groups (i.e., 0 or $1-2$ exacerbations).

Baseline
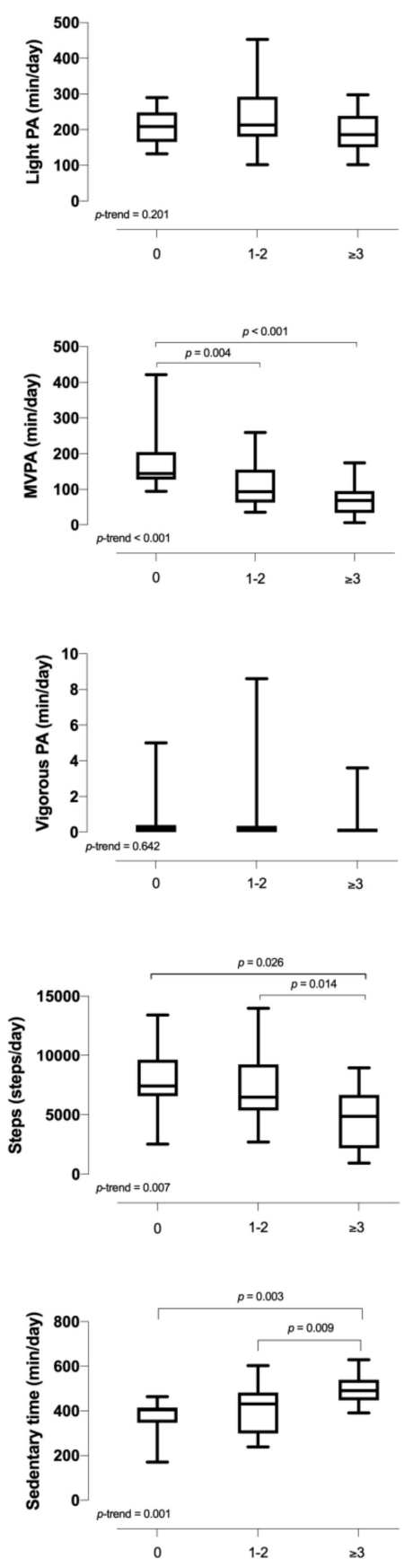

Number of exacerbations
Follow-up
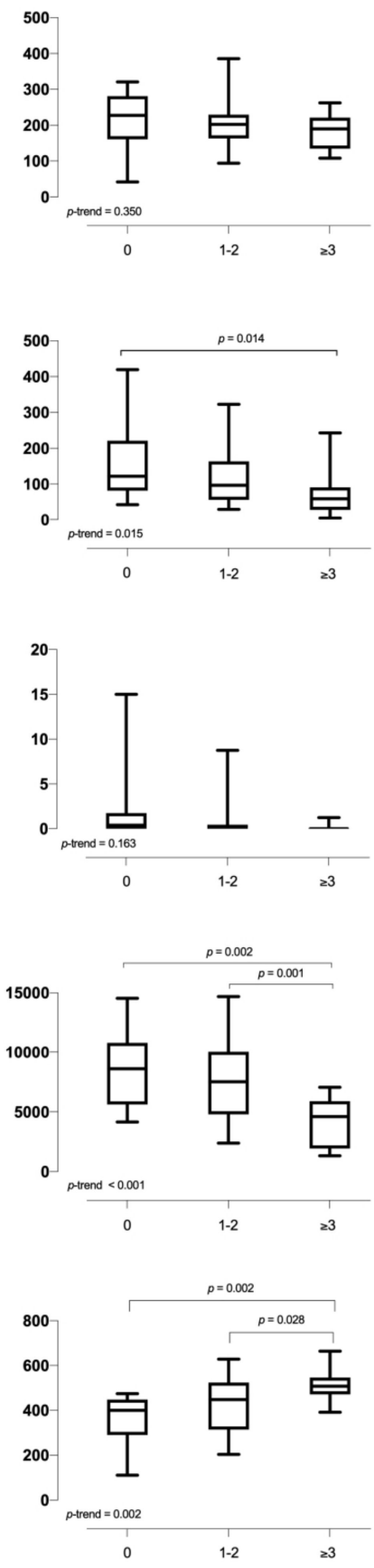

Number of exacerbations

Figure 2. Physical activity and sedentary behaviour at baseline and follow-up according to number of exacerbations. The box and whisker plots show the mean \pm SD for each physical activity variable and sedentary time by the number of exacerbations $(0,1-2$, and $\geq 3)$. The left and right figures show the data for baseline and one year, respectively. Abbreviations: min, minutes; MVPA, moderate-tovigorous physical activity; PA, physical activity. 


\section{Discussion}

To the best of our knowledge, this is the first study to have (1) evaluated and categorised patients with bronchiectasis by their physical activity and sedentary levels at baseline and one year, (2) identified and characterised those patients who deteriorated to become most 'inactive + sedentary' after one year, and (3) associated this shift to the number of exacerbations during the follow-up.

In our previous study, patients with bronchiectasis who walked $\leq 6290$ steps day and/or spent $\geq 7.8 \mathrm{~h}$ in sedentary behaviour were at higher risk of hospitalisation in the following year; concluding that physical activity and sedentary behaviour were a determinant for hospitalisation of bronchiectasis [8]. In the present study, the number of exacerbations during the follow-up was a determinant for changing physical activity and sedentary behaviour in patients with bronchiectasis. Likewise, Bradley et al. [22] reported that patients with bronchiectasis and low physical activity levels showed increased severity, which may have been related to their physical impairment, thereby more exacerbations. MartínezGarcía et al. [5] also showed that there is a specific group of patients with bronchiectasis who are characterised by a high frequency of exacerbations (at least two) or a hospitalisation per year; specifically, it was shown that these patients had a worse five-year all-cause mortality independent to the initial severity of bronchiectasis. These data, combined with the present results, indicate that a high frequency of exacerbations may be associated with declining physical activity levels and increasing sedentary behaviour over time rather than with the severity of exacerbations (reflected by hospitalisation).

In similar populations, such as COPD, Moy et al. [23] showed that lower daily step count was associated with significantly higher rates of acute exacerbations and hospitalisations. Donaire et al. [24] also reported that an increase of 1000 steps daily, performed at low average intensity, reduced the risk of hospitalisation by $20 \%$, whereas Nguyen et al. [25] reported that there was a significant risk reduction (34\%) in 30-day readmissions among patients with COPD who reported engaging in any physical activity. Regarding sedentary behaviour, this has been associated with more exacerbations [26] and higher mortality [27]. Previous observational studies have consistently shown that physical inactivity is associated with an increased risk of hospitalisations and mortality in patients with COPD [28-32]. According to our results, the pattern of decline in physical activity and increase in sedentary behaviour was associated with the number of exacerbations in bronchiectasis; hence, we hypothesise that this may be strongly associated with a worse prognosis. Therefore, these findings highlight the necessity of including assessments for both physical activity and sedentary behaviour in routine clinical practice. PR programs have demonstrated improvements in exercise capacity and health related quality of life in patients with bronchiectasis. However, there is no evidence related to the sustainability of the effects achieved by the exercise training and the importance of the behaviour change as a challenge in the management of patients with bronchiectasis [33]. Hence, more observational and interventional studies are also needed to describe and improve physical activity and sedentary behaviour in the bronchiectasis population. In terms of physical activity intensity, the group with $\geq 3$ exacerbations were least active (lowest MVPA and steps per day, with the highest sedentary time) compared with the groups that had 0 or 1-2 exacerbations during follow-up. There was no difference when assessing light physical activity and exercise capacity. This finding is consistent with our previous study where hospitalised patients walked fewer steps per day, spent more time being sedentary, and had lower levels of MVPA compared with their peers who were not hospitalised. Although the intensity of physical activity seems related to a reduction in exacerbation risk and disease severity, more studies are needed for clarification. Bradley et al. [21] reported that MVPA in bouts of $\geq 10 \mathrm{~min}$ correlated with QoL-B Social Functioning and that patients with moderate/severe disease spent significantly less time in daily total MVPA. In our study, social, physical, and role function domains of the QoL-B were statistically different between groups at follow-up, and these differences were greater than the minimal 
important difference [34]. It seems that low physical activity and high sedentary behaviour could be associated with a higher decline in quality of life after one year of follow-up.

Exacerbations, with or without hospitalisation, hasten acute physical activity deterioration and inactivity in patients with COPD [35-40]. However, the determinants of physical activity change over time are poorly understood [5]. In our longitudinal analysis, 18 patients (34\%) switched from more active or non-sedentary groups to more inactive and/or sedentary groups over one year. Among those patients, 10 (55\%) switched directly to the worst group, and except for the number of exacerbations, not other clinical or functional characteristic (i.e., BSI score, lung function, dyspnoea, or exercise capacity) was associated with this change. Likewise, Bradley et al. [21] reported that neither lung function ( $\mathrm{FEV}_{1} \%$ predicted) nor disease severity (BSI score) was correlated with sedentary behaviour in patients with bronchiectasis. Data collected from patients with COPD have shown that physical activity decliners vary from $35 \%$ to $59 \%$ over time [41,42], but the clinical characteristics could not predict or explain the subsequent patterns of decline, included the number of exacerbations [42-45]. This indicates that the common clinical and functional assessments are unsuitable for use as indicators of risk of physical activity decline and/or increase in sedentary behaviour, which further highlights the need for further longitudinal and objective assessment in clinical settings. Moving forward, the whole spectrum of those behaviours must be included, accounting for the potential impacts of psychological, interpersonal, social, and environmental correlates in the assessment $[5,42,46]$.

A major strength of our study is the use of validated and objective devices to assess physical activity and sedentary behaviour over a one year follow-up period. The results provide novel and valuable information that will require allied respiratory health professionals to design interventions that can enhance physical activity and reduce sedentary behaviour in patients with bronchiectasis.

However, the study also has limitations. The sample size $(n=53)$ may result in a large type II error and conclusions that can be drawn are limited. This limitation notwithstanding, the rigorous approach to the study underpins our confidence in its findings and their clinical relevance. In addition, possible over-fitting and instability of the variables due to the limited sample size in the logistic regression model evaluating the change in physical activity and sedentary behaviour after one year in patients with bronchiectasis, was measured by internal validation using ordinary nonparametric bootstrapping, which demonstrated robust results. Other measurements related to physical activity and sedentary behaviour, such as muscle strength, were missing and may have improved the analysis. This should be addressed in future research. Considering the heterogeneity of physical activity and sedentary behaviour levels among countries and cultures, the study results may not be generalizable to other settings. Further studies are, therefore, needed, with larger number of patients included that target different bronchiectasis populations in other regions or medical settings.

\section{Conclusions}

In this broad assessment of clinical, functional, and sociodemographic factors, a decline in physical activity levels and increase in sedentary behaviour over one year in patients with bronchiectasis was independently associated with the number of exacerbations. Exacerbation prevention may appear as a key factor in relation to physical activity and sedentary behaviour in patients with bronchiectasis.

Author Contributions: V.A.-S. had full access to all of the data in the study and takes responsibility for the integrity of the data and the accuracy of the data analysis. V.A.-S. designed, developed the study protocol and collected the data from patients. V.A.-S., A.A.-E. and E.G.-S. participated in the statistical analysis, data interpretation and in the writing of the manuscript. V.A.-S, A.A.-E, P.O., L.F.-B., L.B., R.A., E.G.-S., and A.T. have read the final version of the manuscript, fully approve it and qualify for authorship. 
Funding: This research was funded by ISCIII-FEDER (FIS: PI18000145 to A.T. and L.F-B.), CIBER (PI01/2018, to A.T. and L.F-B.), SEPAR 628/2018, ICREA Academia (to A.T.), CB 06/06/0028/CIBER de enfermedades respiratorias, Ciber it is an initiative of ISCIII, 2.603/IDIBAPS, SGR/Generalitat de Catalunya (coordinated by A.T.).

Institutional Review Board Statement: The study was conducted according to the guidelines of the Declaration of Helsinki, and approved by the Clinical Research Ethics Committee of the Hospital Clinic (Ethics Approval Reference: HCB/2016/0012).

Informed Consent Statement: Informed consent was obtained from all subjects involved in the study. Acknowledgments: The authors would like to thank the patients for taking part in the study.

Conflicts of Interest: The authors declare no conflict of interest.

\section{References}

1. King, P.T.; Holdsworth, S.R.; Freezer, N.J.; Villanueva, E.; Holmes, P.W. Characterisation of the onset and presenting clinical features of adult bronchiectasis. Respir. Med. 2006, 100, 2183-2189. [CrossRef] [PubMed]

2. Hill, A.T.; Haworth, C.S.; Aliberti, S.; Barker, A.; Blasi, F.; Boersma, W.; Chalmers, J.D.; de Soyza, A.; Dimakou, K.; Elborn, J.S.; et al. Pulmonary exacerbation in adults with bronchiectasis: A consensus definition for clinical research. Eur. Respir. J. 2017, 49, 1700051. [CrossRef] [PubMed]

3. Bell, S.C.; Elborn, J.S.; Byrnes, C.A. Bronchiectasis: Treatment decisions for pulmonary exacerbations and their prevention. Respirology 2018, 11, 1006-1022. [CrossRef]

4. Cantón, R.; Máiz, L.; Escribano, A.; Olveira, C.; Oliver, A.; Asensio, O.; Gartner, S.; Roma, E.; Quintana-Gallego, E.; Salcedo, A.; et al. Consenso español para la prevención y el tratamiento de la infección bronquial por Pseudomonas aeruginosa en el paciente con fibrosis quística. Arch. Bronconeumol. 2015, 51, 140-150. [CrossRef]

5. Martinez-Garcia, M.Á.; Athanazio, R.; Gramblicka, G.; Corso, M.; Cavalcanti Lundgren, F.; Fernandes de Figueiredo, M.; Arancibia, F.; Rached, S.; Girón, R.; Máiz Carro, L.; et al. Prognostic Value of Frequent Exacerbations in Bronchiectasis: The Relationship with Disease Severity. Arch. Bronconeumol. 2019, 55, 81-87. [CrossRef] [PubMed]

6. Gimeno-Santos, E.; Frei, A.; Steurer-Stey, C.; de Batlle, J.; Rabinovich, R.A.; Raste, Y.; Hopkinson, N.S.; Polkey, M.I.; van Remoortel, H.; Troosters, T.; et al. Determinants and outcomes of physical activity in patients with COPD: A systematic review. Thorax 2014, 69, 731-739. [CrossRef] [PubMed]

7. Ramos, M.; Lamotte, M.; Gerlier, L.; Svangren, P.; Miquel-Cases, A.; Haughney, J. Cost-effectiveness of physical activity in the management of COPD patients in the UK. Int. J. COPD 2019, 14, 227-239. [CrossRef] [PubMed]

8. Alcaraz-Serrano, V.; Gimeno-Santos, E.; Scioscia, G.; Gabarrús, A.; Navarro, A.; Herrero-Cortina, B.; Amaro, R.; Fernández-Barat, L.; Torres, A. Association between physical activity and risk of hospitalisation in bronchiectasis. Eur. Respir. J. 2020, 55, 1-9. [CrossRef] [PubMed]

9. World Health Organization. WHO Guidelines on physical activity and sedentary behaviour. Available online: https://www. who.int/publications/i/item/9789240015128 (accessed on 24 December 2020).

10. Schneider, L.P.; Furlanetto, K.C.; Rodrigues, A.; Lopes, J.R.; Hernandes, N.A.; Pitta, F. Sedentary Behaviour and Physical Inactivity in Patients with Chronic Obstructive Pulmonary Disease: Two Sides of the Same Coin? COPD 2018, 15, 432-438. [CrossRef] [PubMed]

11. Hester, K.L.M.; Macfarlane, J.G.; Tedd, H.; Jary, H.; McAlinden, P.; Rostron, L.; Small, T.; Newton, J.L.; De Soyza, A. Fatigue in bronchiectasis. QJM 2012, 105, 235-240. [CrossRef]

12. Miller, M.R.; Hankinson, J.; Brusasco, V.; Burgos, F.; Casaburi, R.; Coates, A.; Crapo, R.; Enright, P.; van der Grinten, C.P.M.; Gustafsson, P.; et al. Standardisation of spirometry. Eur. Respir. J. 2005, 26, 319-338. [CrossRef] [PubMed]

13. Holland, A.E.; Spruit, M.A.; Troosters, T.; Puhan, M.A.; Pepin, V.; Saey, D.; McCormack, M.C.; Carlin, B.W.; Sciurba, F.C.; Pitta, F.; et al. An official European Respiratory Society/American Thoracic Society technical standard: Field walking tests in chronic respiratory disease. Eur. Respir. J. 2014, 44, 1428-1446. [CrossRef]

14. Olveira, C.; Olveira, G.; Espildora, F.; Giron, R.M.; Muñoz, G.; Quittner, A.L.; Martinez-Garcia, M.-A. Validation of a Quality of Life Questionnaire for Bronchiectasis: Psychometric analyses of the Spanish QOL-B-V3.0. Qual. Life Res. 2014, 23, 1279-1292. [CrossRef] [PubMed]

15. Muñoz, G.; Buxó, M.; De Gracia, J.; Olveira, C.; Martinez-Garcia, M.A.; Giron, R.; Polverino, E.; Alvarez, A.; Birring, S.S.; Vendrell, M. Validation of a Spanish version of the Leicester Cough Questionnaire in non-cystic fibrosis bronchiectasis. Chron. Respir. Dis. 2016, 13, 128-136. [CrossRef] [PubMed]

16. Chalmers, J.D.; Goeminne, P.; Aliberti, S.; McDonnel, M.J.; Lonni, S.; Davidson, J.; Poppelwell, L.; Salih, W.; Pesci, A.; Dupont, L.J.; et al. The bronchiectasis severity index. An international derivation and validation study. Am. J. Respir. Crit. Care Med. 2014, 189, 576-585. [CrossRef] [PubMed]

17. Chalmers, J.D.; Aliberti, S.; Filonenko, A.; Shteinberg, M.; Goeminne, P.C.; Hill, A.T.; Fardon, T.C.; Obradovic, D.; Gerlinger, C.; Sotgiu, G.; et al. Characterization of the "frequent exacerbator phenotype" in bronchiectasis. Am. J. Respir. Crit. Care Med. 2018, 197, 1410-1420. [CrossRef] [PubMed] 
18. Demeyer, H.; Burtin, C.; Van Remoortel, H.; Hornikx, M.; Langer, D.; Decramer, M.; Gosselink, R.; Janssens, W.; Troosters, T. Standardizing the Analysis of Physical Activity in Patients with COPD Following a Pulmonary Rehabilitation Program. Chest 2014, 146, 318-327. [CrossRef]

19. Ainsworth, B.E.; Haskell, W.L.; Whitt, M.C.; Irwin, M.L.; Swartz, A.M.; Strath, S.J.; O’Brien, W.L.; Bassett, D.R.; Schmitz, K.H.; Emplaincourt, P.O.; et al. Compendium of physical activities: An update of activity codes and MET intensities. Med. Sci. Sports Exerc. 2000, 32, S498-S504. [CrossRef]

20. Hosmer, D.; Lemeshow, S.; Sturdivant, R.X. Applied Logistic Regression; Wiley: New York, NY, USA, 1989.

21. Collett, D. Modelling Binary Data; Chapman and Hall: London, UK, 1991.

22. Bradley, J.M.; Wilson, J.J.; Hayes, K.; Kent, L.; McDonough, S.; Tully, M.A.; Bradbury, I.; Kirk, A.; Cosgrove, D.; Convery, R.; et al. Sedentary behaviour and physical activity in bronchiectasis: A cross-sectional study. BMC Pulm. Med. 2015, 15, 61. [CrossRef]

23. Moy, M.L.; Teylan, M.; Weston, N.A.; Gagnon, D.R.; Garshick, E. Daily Step Count Predicts Acute Exacerbations in a US Cohort with COPD. PLoS ONE 2013, 8, e60400. [CrossRef]

24. Donaire-Gonzalez, D.; Gimeno-Santos, E.; Balcells, E.; De Batlle, J.; Ramon, M.A.; Rodriguez, E.; Farrero, E.; Benet, M.; Guerra, S.; Sauleda, J.; et al. Benefits of physical activity on COPD hospitalisation depend on intensity. Eur. Respir. J. 2015, 46, 1281-1289. [CrossRef]

25. Nguyen, H.Q.; Chu, L.; Liu, I.L.A.; Lee, J.S.; Suh, D.; Korotzer, B.; Yuen, G.; Desai, S.; Coleman, K.J.; Xiang, A.H.; et al. Associations between physical activity and 30-day readmission risk in chronic obstructive pulmonary disease. Ann. Am. Thorac. Soc. 2014, 11, 695-705. [CrossRef] [PubMed]

26. Hartman, J.E.; Boezen, H.M.; de Greef, M.H.; Ten Hacken, N.H. Physical and psychosocial factors associated with physical activity in patients with chronic obstructive pulmonary disease. Arch. Phys. Med. Rehabil. 2013, 94, 2396-2402. [CrossRef]

27. Furlanetto, K.C.; Donária, L.; Schneider, L.P.; Lopes, J.R.; Ribeiro, M.; Fernandes, K.B.; Hernandes, N.A.; Pitta, F. Sedentary Behavior Is an Independent Predictor of Mortality in Subjects With COPD. Respir. Care 2017, 62, 579-587. [CrossRef]

28. Garcia-Aymerich, J.; Lange, P.; Benet, M.; Schnohr, P.; Antó, J.M. Regular physical activity reduces hospital admission and mortality in chronic obstructive pulmonary disease: A population based cohort study. Thorax 2006, 61, 772-778. [CrossRef] [PubMed]

29. Garcia-Rio, F.; Rojo, B.; Casitas, R.; Lores, V.; Madero, R.; Romero, D.; Galera, R.; Villasante, C. Prognostic value of the objective measurement of daily physical activity in patients with COPD. Chest 2012, 142, 338-346. [CrossRef] [PubMed]

30. Vaes, A.W.; Garcia-Aymerich, J.; Marott, J.L.; Benet, M.; Groenen, M.T.J.; Schnohr, P.; Franssen, F.M.E.; Vestbo, J.; Wouters, E.F.M.; Lange, P.; et al. Changes in physical activity and all-cause mortality in COPD. Eur. Respir. J. 2014, 44, 1199-1209. [CrossRef] [PubMed]

31. Esteban, C.; Garcia-Gutierrez, S.; Legarreta, M.J.; Anton-Ladislao, A.; Gonzalez, N.; Lafuente, I.; Fernandez de Larrea, N.; Vidal, S.; Bare, M.; Quintana, J.M. One-year Mortality in COPD After an Exacerbation: The Effect of Physical Activity Changes during the Event. COPD 2016, 13, 718-725. [CrossRef]

32. Waschki, B.; Kirsten, A.; Holz, O.; Müller, K.C.; Meyer, T.; Watz, H.; Magnussen, H. Physical activity is the strongest predictor of all-cause mortality in patients with COPD: A prospective cohort study. Chest 2011, 140, 331-342. [CrossRef] [PubMed]

33. Lee, A.L.; Hill, C.J.; McDonald, C.F.; Holland, A.E. Pulmonary rehabilitation in individuals with non-cystic fibrosis bronchiectasis: A systematic review. Arch. Phys. Med. Rehabil. 2017, 98, 774-782. [CrossRef] [PubMed]

34. Quittner, A.L.; O'Donnell, A.E.; Salathe, M.A.; Lewis, S.A.; Li, X.; Montgomery, A.B.; O'Riordan, T.G.; Barker, A.F. Quality of life questionnaire-bronchiectasis: Final psychometric analyses and determination of minimal important difference scores. Thorax 2015, 70, 12-20. [CrossRef]

35. Pitta, F.; Troosters, T.; Probst, V.S.; Spruit, M.A.; Decramer, M.; Gosselink, R. Physical activity and hospitalization for exacerbation of COPD. Chest 2006, 129, 536-544. [CrossRef]

36. Alahmari, A.D.; Patel, A.R.C.; Kowlessar, B.S.; Mackay, A.J.; Singh, R.; Wedzicha, J.A.; Donaldson, G.C. Daily activity during stability and exacerbation of chronic obstructive pulmonary disease. BMC Pulm. Med. 2014, 14, 98. [CrossRef] [PubMed]

37. Donaldson, G.C.; Wilkinson, T.M.A.; Hurst, J.R.; Perera, W.R.; Wedzicha, J.A. Exacerbations and time spent outdoors in chronic obstructive pulmonary disease. Am. J. Respir. Crit. Care Med. 2005, 171, 446-452. [CrossRef] [PubMed]

38. Borges, R.C.; Carvalho, C.R.F. Physical activity in daily life in Brazilian COPD patients during and after exacerbation. COPD 2012, 9, 596-602. [CrossRef]

39. Demeyer, H.; Costilla-Frias, M.; Louvaris, Z.; Gimeno-Santos, E.; Tabberer, M.; Rabinovich, R.A.; de Jong, C.; Polkey, M.I.; Hopkinson, N.S.; Karlsson, N.; et al. Both moderate and severe exacerbations accelerate physical activity decline in COPD patients. Eur. Respir. J. 2018, 51, 1702110. [CrossRef] [PubMed]

40. Ehsan, M.; Khan, R.; Wakefield, D.; Qureshi, A.; Murray, L.; ZuWallack, R.; Leidy, N.K. A longitudinal study evaluating the effect of exacerbations on physical activity in patients with chronic obstructive pulmonary disease. Ann. Am. Thorac. Soc. 2013, 10, 559-564. [CrossRef]

41. Sievi, N.A.; Brack, T.; Brutsche, M.H.; Frey, M.; Irani, S.; Leuppi, J.D.; Thurnheer, R.; Kohler, M.; Clarenbach, C.F. “Can do, don't do" are not the lazy ones: A longitudinal study on physical functioning in patients with COPD. Respir. Res. 2020, 21, 27. [CrossRef] [PubMed] 
42. Koreny, M.; Demeyer, H.; Benet, M.; Arbillaga-Etxarri, A.; Balcells, E.; Barberan-Garcia, A.; Gimeno-Santos, E.; Hopkinson, N.S.; De Jong, C.; Karlsson, N.; et al. Patterns of Physical Activity Progression in Patients With COPD. Arch. Bronconeumol. 2020, S0300-2896, 30280-30285. [CrossRef] [PubMed]

43. Clarenbach, C.F.; Sievi, N.A.; Haile, S.R.; Brack, T.; Brutsche, M.H.; Frey, M.; Irani, S.; Leuppi, J.D.; Thurnheer, R.; Kohler, M. Determinants of annual change in physical activity in COPD. Respirology 2017, 22, 1133-1139. [CrossRef]

44. Sievi, N.A.; Brack, T.; Brutsche, M.H.; Frey, M.; Irani, S.; Leuppi, J.D.; Thurnheer, R.; Kohler, M.; Clarenbach, C.F. Physical activity declines in COPD while exercise capacity remains stable: A longitudinal study over 5 years. Respir. Med. 2018, 141, 1-6. [CrossRef] [PubMed]

45. Sievi, N.A.; Kohler, M.; Thurnheer, R.; Leuppi, J.D.; Irani, S.; Frey, M.; Brutsche, M.; Brack, T.; Clarenbach, C.F. No impact of exacerbation frequency and severity on the physical activity decline in COPD: A long-term observation. Int. J. COPD 2019, 14, 431-437. [CrossRef]

46. Arbillaga-Etxarri, A.; Gimeno-Santos, E.; Barberan-Garcia, A.; Benet, M.; Borrell, E.; Dadvand, P.; Foraster, M.; Marín, A.; Monteagudo, M.; Rodríguez-Roisin, R.; et al. Socio-environmental correlates of physical activity in patients with chronic obstructive pulmonary disease (COPD). Thorax 2017, 72, 796-802. [CrossRef] [PubMed] 